\title{
HANS JONAS - CLONAGEM REPRODUTIVA HUMANA E CUIDADO CRIATIVO ${ }^{1}$
}

Hans Jonas, buman reproductive cloning and creative care

\section{Wendell E. S. Lopes}

RESUMO: O presente trabalho visa apresentar uma reflexão ética sobre uma das mais intrigantes biotecnologias da atualidade: a clonagem reprodutiva humana. Mais especificamente, o objetivo é explorar o sentido da crítica do filósofo Hans Jonas à referida modalidade biotecnológica, derivando dessa crítica um princípio que chamaremos de "Cuidado Criativo" princípio que se pretende uma interdição moral à clonagem reprodutiva humana.

PALAVRAS-CHAVE: Clonagem; Ética; Cuidado criativo.

ABSTRACT: The present paper aims to presents an ethical reflection on one of the most intriguing biotechnologies nowadays: cloning. More specifically, the goal is to explore the meaning of Hans Jonas criticism on cloning, deriving from his criticism a principle which we will call "Creative Care" - a principle that intends to be a moral one prohibiting human reproductive cloning.

KEYWORDS: Cloning; Ethics; Creative care.

Para iniciar este ensaio, permitam-me citar de saída o sempre eloquente Peter Sloterdijk: “imaginariamente, já vivemos hoje em um calendário post Dolly creatam” (2000, p. 107-08) - isto é, em um mundo que tem bem definido para si um antes e um depois de Dolly. O nascimento do mamífero (não humano) mais famoso da história tem sido fonte de forte controvérsia e agitação, haja vista a possibilidade real de aplicação da clonagem para a reprodução humana. Os enredos de tal possibilidade ainda estão por aí a nos espreitar. Naturalmente, sabe-se que a clonagem reprodutiva ainda goza hoje de muitos problemas relacionados à sua eficiência e segurança. Por um lado, o índice de sucessos é baixíssimo - o nascimento de Dolly exigiu nada menos que a cultura de 430 ovócitos de mais de 40 ovelhas, com o resultado de 277 “embriões reconstruídos”, dos quais apenas 29 embriões se desenvolveram normalmente até o estágio de blastocisto, sendo

\footnotetext{
${ }^{1} \mathrm{O}$ seguinte ensaio é a versão revista e ampliada de uma versão preliminar apresentada no "II Colóquio Internacional NEPC: biotecnologias e regulações", realizado na Universidade Federal de Minas Gerais/MG, no dia 29 de abril de 2011.
} 
implantados em 13 ovelhas com um sucesso único: Dolly (cf. GRIFFIN, 2002, p. 284); e mais: os baixos resultados (entre 1 a 4\%) permanecem para todas as espécies (cf. PENNISI \& VOGEL, 2000). Por outro lado, o número de problemas que a técnica apresenta é notável: em todas as espécies (ainda que não em todos os indivíduos) há registros de incidência de anormalidades de extrema severidade. A lista engloba (a) morte prematura (cf. RENARD et al., 1999; KAHN, 2000, p. 225; GRIFFIN, 2002, p. 285), (b) anomalias em longo prazo como problemas respiratórios, hepáticos, renais, imunológicos - existindo relatos, inclusive, de ovelhas com vasos sanguíneos vinte vezes mais largos que o normal (cf. KLOTZKO, 2004, p. 118) e também com o próprio tamanho muito maior que o normal (cf. GRIFFIN, 2002, p. 285), e (c) envelhecimento precoce (cf. KAHN, 2000, p. 226; SHIELS et al., 1999; ALLHOFF, 2004, p. 29). Alguns cientistas - embora não todos - pensam até mesmo que todo clone é defeituoso. Não sem motivos, o consenso atual (na maioria dos países ocidentais) quanto à clonagem reprodutiva humana é a legislação contrária à sua aplicação.

Apesar disso, é certo também que a prospectiva é de aperfeiçoamento da técnica e de seus problemas, ao que já se pode ouvir alguns defenderem que "deveríamos não insistir em um critério que exija riscos que sejam menores do que aqueles que aceitamos para a reprodução sexual, ou em outras formas de reprodução assistida...” (BUCHANAN et al, 2000, p. 199). Tendo em vista principalmente essa última insistência que certamente não é um caso isolado, e partindo de uma situação hipotética, mas bastante plausível, em que a clonagem reprodutiva humana seria segura ou pelo menos aceitável do ponto de vista técnico - ao custo, claro, da experimentação com animais, e, nesse sentido, para desagrado de seus defensores -, buscaremos demonstrar em que sentido a clonagem mesmo em uma situação ideal de temperatura e pressão seria moralmente reprovável. Mais especificamente nosso escopo é explorar o sentido da crítica de Hans Jonas à clonagem, derivando daí um princípio que chamaremos de "cuidado criativo" - princípio este que como uma das facetas da responsabilidade se pretende uma restrição moral à clonagem reprodutiva humana.

Inicialmente, então, devemos começar com Jonas. Do tecido de suas considerações à clonagem duas críticas principais se destacam. A primeira, ele próprio a designa por "crítica existencial". É a ela que irei ater-me primeiro. Para Jonas, a questão ética levantada pela clonagem se refere ao esclarecimento do "que para o próprio clone significa ser um clone" (JONAS, 1974/1980, p. 158; 1985/1987, p. 187). E nessa direção, o que ele busca é uma "certeza transempírica do critério que às vezes concede a contemplação da essência” (JONAS, 1974/1980, p. 158; 1985/1987, p. 187). Devemos então perguntar: qual é a "essência" que, ao ser contemplada, fornece tal certeza? A resposta, podemos ouvir do próprio Jonas: "a questão central 
da essência é aquela da ipseidade sem prejuízo [unprejudiced selfhood/nicht-präjudizierter Selbstheit]" (JONAS, 1974/1980, p. 159; 1985/1987, p. 187). É esse ponto, portanto, o determinante para a comparação do caso do clone com a situação dos gêmeos idênticos. Nessa comparação, o que logo se mostra é a simultaneidade [Gleichreitigkeit] dos gêmeos idênticos, à qual se distingue completamente a desigualdade inerente à condição clone em relação àquele de quem ele é clone uma situação que se estabelece em prejuízo à ipseidade do clone. O problema é exatamente o fato de que, para o clone, “conhecer-se como uma mera cópia de um ser que já se revelou em uma vida anterior deve asfixiar a autenticidade do ser si mesmo e a liberdade de primeiro descobrir a si mesmo... Esse mesmo conhecimento ilícito asfixia a mente-aberta de outrem em relação ao recém e, entretanto, não- tão-recém chegado" (JONAS, 1985/2004, p. 578; 1985/1987, p. 214). É tendo em vista este prejuízo inerente à situação existencial do clone que Jonas vê a necessidade do mandamento moral seguinte: "nunca violar o direito àquela ignorância que é a condição para a possibilidade de ação autêntica; ou: respeitar o direito de cada vida humana de encontrar seu próprio caminho e ser uma surpresa para si mesma” (JONAS, 1974/1980, p. 163; 1985/1987, p. 194).

Com essa breve exposição inicial do primeiro aspecto da posição de Jonas, passo a uma discussão da fortuna crítica que seu argumento existencial encontrou. Tal argumento foi considerado por boa parte dos críticos como bastante promissor e profundo, mas apesar disso não suficiente. Assim se passa primeiro com a crítica de Steinbock. A autora acusa Jonas de cair no que ela chama de "a falácia do determinismo genético". Aos seus olhos, a crítica de Jonas seria a de que dado a sua condição - enquanto distinta à do gêmeo síncrono - o clone "seria incapaz de criar e de se tornar seu próprio Eu [self]" (2000, p. 72 [grifo nosso]). A autora chega a sugerir que a pessoa clonada poderia muito bem ter uma boa idéia de como estaria à idade de cinqüenta anos, mas não teria "as mesmas habilidades e talentos que as de seu progenitor, pois [esses] dependem pelo menos de fatores ambientais tanto quanto da herança genética" (STEINBOCK, 2000, p. 72). Por sua vez, Valk considera que para Jonas "um futuro aberto é uma pré- condição essencial para a criatividade pessoal" e, portanto, fator determinante do "direito [que cada um tem] de encontrar seu próprio caminho na vida" (1997, p. 85). Mas para ele tal posição seria como que a "defesa de uma opção de avestruz" (VALK, 1997, p. 90).

De modo geral, essas duas críticas - que no fundo são complementares - se tornaram regra quando o assunto é o argumento existencial de Jonas. Frente a elas, entretanto, é preciso esclarecer dois grandes equívocos. Primeiro, é bastante claro que Jonas distingue "unicidade [uniqueness] de genótipo" e "unicidade de ser" (cf. JONAS, 1974/1980, p. 160), e isso pela seguinte razão: 
independente de se o 'conhecimento' [quanto à determinação genética] é verdadeiro ou falso (existem razões para se acreditar que essencialmente é falso em si), ele é pernicioso para a tarefa da ipseidade: existencialmente significativo é o que o indivíduo clonado pensa - é impelido a pensar - sobre si mesmo, não o que ele 'é', no sentido substancial de ser. Em suma, ele é antecipadamente roubado da liberdade que apenas sob a proteção da ignorância pode ter êxito (JONAS, 1974/1980, p. 162; 1985/1987, p. 192)2.

Esse primeiro esclarecimento nos leva a outro, e que no fundo é uma resposta à crítica de Valk. O que se deve entender é que "futuro aberto" não é um direito, mas um fato biológico, que tanto mais se acentua quanto mais ipseidade possui um organismo (cf. JONAS, 1966/2001, p. 83-86). A filosofia da biologia elaborada por Jonas defende explicitamente a idéia de que "um organismo também tem uma existência subjetiva [subjektives Dasein]" (JONAS, 1991, p. 106), e nesse sentido um horizonte de transcendência e abertura já se encontra em toda experiência propriamente orgânica. Assim, seu argumento não gravita fundamentalmente em torno do problema da qualidade de vida do clone - o problema não é psicológico, mas ontológico, o que quer dizer que o que conta é a condição existencial como tal, que no caso do clone se encontra prejudicada - e é desigual - já de saída. A questão é o prejuízo no horizonte de abertura, que embora seja, de fato, aberto, não é radicalmente aberto - é isto o que se quer dizer com a afirmação de que a clonagem infringe o "direito à ignorância”, "indispensável para a liberdade existencial" (JONAS, 1985/2004, p. 578; 1985/1987, p. 214) - onde "liberdade existencial", claro, não se confunde com livre-arbítrio (cf. PRUSAK, 2008, p. 321-323).

Esses são, a meu ver, alguns dos elementos mais importantes da crítica existencial. Ao se passar para a outra ponta do argumento de Jonas, encontramos agora a crítica de que a clonagem é "por seu método, a forma de manipulação genética mais arbitrária e ao mesmo tempo, por seu objetivo, a mais escrava" (JONAS, 1974/1980, p. 154; 1985/1987, p. 179), pois ao contrário da "modificação arbitrária da substância hereditária" ela busca um controle fixador em detrimento do acaso da variabilidade. Portanto, ela "não pretende representar uma viagem ao desconhecido, mas justamente em direção ao mais conhecido” (JONAS, 1985/1987, p. 179).

\footnotetext{
2 Algo bem próximo do que salienta Jonas, aqui, parece se encontrar mais recentemente, com um novo tom, no que Holm defende com seu "life in the shadow argument": "o argumento da vida-na-sombra não se baseia na falsa premissa de que podemos fazer uma inferência do genótipo para o fenótipo (psicológico ou relativo à personalidade), mas apenas na premissa verdadeira de que há uma forte tendência pública em fazer tal inferência. Isto significa que as conclusões do argumento se seguem enquanto esta premissa empírica permanecer verdadeira"; e o autor ainda ressalta: "é provavelmente fantasioso esperar uma mudança muito grande nas percepções do público sobre a genética, mesmo que façamos uma campanha extremamente forte de informação pública" (HOLM, 2001, p. 206).
} 
Esse argumento contra a clonagem ficou rotulado como o "argumento da variabilidade" e logo recebeu também críticas dos defensores da clonagem. O argumento dos críticos se reduz em linhas gerais à afirmação de ceticismo quanto a uma grande adesão e difusão da clonagem reprodutiva na esfera pública, o que por sua vez não geraria efeitos tão consideráveis quanto à variação do pool gênico (cf. HARRIS, 1997, p. 356; Singer, 2001, p. 162; KLOTZKO, 2007, p. 131). Não obstante, quero antes fazer notar alguns problemas implícitos a essa idéia: não me interessa tanto, aqui, se, de fato, a clonagem levaria a uma queda considerável da variabilidade genética. Antes, o que gostaria de chamar a atenção se refere ao fato de que esse contraargumento não se baseia em evidências, mas na suposição de que as pessoas evitariam escolher a clonagem por ser esta uma forma pior e mais drástica de ter "filhos". Se é uma opção declaradamente pior - pois do contrário seria necessário dizer que a procura pela clonagem aumentaria - por que então defendê-la? E mais ainda: por que a opção pelo fixar em detrimento da variabilidade? Ou se se preferir: por que a lógica do mesmo em detrimento da lógica da alteridade? À primeira pergunta só se pode responder em termos de custo-benefício. A segunda, por sua vez, deve o ser em termos de reivindicação de um direito específico que precisa responder por sua legitimidade. Ambos os pontos precisam ser tratados.

Tendo explicitado até aqui as duas pontas do argumento jonasiano contra a clonagem e deixando entrevisto os problemas que levanta, posso agora derivar - e defender - o princípio ético que chamo de cuidado criativo. O que ele propõe é apenas que os pais não causem deliberadamente dano existencial/ontológico aos seus filhos, mas antes se baseiem em um paradigma de adoção. Tal princípio possui uma dupla orientação. Vejamos, então, o que está implicado em cada um de seus polos orientadores.

Num primeiro plano, note-se inicialmente que tal principio é antes de tudo um princípio ético antes que propriamente político (como o princípio da "autonomia procriativa) e tem um sentido negativo, isto é, ele não defende primeiramente o que positivamente se deveria fazer (ainda que possua tal orientação complementar também, como veremos), mas antes destaca o que não se deveria fazer ou o que se deveria evitar: não causar dano existencial-ontológico. Nesse sentido, o princípio do cuidado criativo não se identifica também com um princípio da "beneficência procriativa" (SAVULESCU, 2001), pois pede algo muito diferente do que a escolha do melhor (e entenda-se "melhor" aqui no sentido de melhor condição de nascimento) - algo que gera, inclusive, consequências teóricas e práticas absurdas (cf. ALLHOFF, 2004, p. 30-31; e STEINBERG, 2004, p. 27-28). O que nosso princípio pede, ao contrário, ao reivindicar que o direito à ignorância seja preservado é simplesmente uma condição de igualdade antropológica (em termos existenciais-ontológicos). Com esta primeira orientação, ele precisa, entretanto, 
responder a críticas que se baseiam em termos de custo-benefício. Por exemplo, poder-se-ia objetar contra o princípio proposto a afirmação de que uma vida prejudicada é ainda a única possibilidade para o clone e, portanto, de seu interesse, uma vez que não é pior do que não viver de modo algum (cf. HARRIS, 2004, p. 70; SINGER, 2001, p. 164). Mas em resposta é preciso dizer que esse tipo de argumento é uma impostura e expressa apenas o desespero retórico daquele que já reconhece que pratica o pior e ainda busca se justificar com o apelo emotivo a um suposto valor da vida em detrimento do não existir; pior: tal argumento simplesmente justifica trazer à luz monstros, pois, afinal, melhor uma vida de monstro do que vida nenhuma. Trata-se de um exemplo típico de mera santificação indevida dos meios em função de um fim desejado ${ }^{3}$.

Seguindo numa mesma direção, mas com um acento ligeiramente diferente, pode-se ouvir outra crítica. Harris, por exemplo, observa que a pobreza é um prognóstico preciso de maus resultados para a prole, embora seja bem diferente "dizer que não se deveria permitir que o pobre tivesse filhos" (2004, p. 74 e também p. 84-85). Brock, por sua vez, oferece um novo capítulo desse argumento: "os mais possíveis danos para uma criança clonada são menos sérios do que os danos genéticos com os quais os pais podem atualmente permitir que sua descendência seja concebida ou nasça" (1998, p. 145). E Singer (2001, p. 164), por fim, segue o estilo de tal argumento ao sugerir que a aceitação dos riscos no nascimento de um recém-nascido prematuro é idêntica a de um indivíduo clonado. Mas contra essas críticas pode-se dizer junto com Prusak que tais críticas "são exemplos do que se tem acostumado chamar de 'argumento do precedente', especificamente 'o argumento nós já fizemos isso (e tudo está bem)'. Esse argumento tem a seguinte forma: 'se uma prática $\mathrm{X}$ foi moralmente aceita no passado, e se a prática $\mathrm{Y}$ é exatamente igual à prática $\mathrm{X}$, então a prática $\mathrm{Y}$ deveria ser moralmente aceita agora e no futuro"'. O erro fundamental do argumento é, como se percebe, comparar exemplos que simplesmente não são análogos, isto é, a prática $\mathrm{X}$, a clonagem, não é idêntica à prática $\mathrm{Y}$, permitir que um pobre ou que uma criança prematura nasça (para que fique claro: um dano físico, psicológico, econômico difere - e muito! - de um dano existencial-ontológico); nem muito menos se assemelha o que está em jogo em cada um dos casos: porque uma coisa é correr um risco inicialmente inesperado (como é o caso com o nascimento de crianças prematuras), outra completamente distinta é gerar deliberadamente uma criança à qual se causa conscientemente um dano (existencial).

\footnotetext{
${ }^{3} \mathrm{O}$ mais incrível na defesa desse argumento, por parte de Harris especificamente, se deve ao fato de que no mesmo livro, intitulado On Cloning, apenas algumas páginas adiante do primeiro argumento referido acima, ele defende exatamente o contrário do que parecia defender: uma vez que a vida da criança - diz ele - sempre "será uma vida totalmente digna, então não podem ser os interesses dessa criança as razões que justificam quaisquer decisões e regulações que a neguem as oportunidades de existência” (HARRIS, 2004, p. 76- 77), isto é, não faz sentido apelar para os interesses futuros da criança para negar existência a ela. Ficamos como alguém diante de um ladrão, sem saber se levanta ou não as mãos.
} 
Pois bem: além desse primeiro aspecto do cuidado criativo é preciso explicitar ainda o que o mesmo possui em estreita relação com a defesa do "argumento da variabilidade": a saber, o cuidado não busca apenas se resguardar do dano, ele também atende a uma lógica da alteridade ou ao que chamaremos de paradigma da adoção. Aqui, nosso princípio visa responder à questão das intenções em jogo na opção pela clonagem. Dentre os muitos motivos de recurso à clonagem, a defesa quanto à aplicação da técnica se concentra hoje em torno da solução de problemas relacionados a progenitores inférteis ou que por algum motivo não podem ter filhos. Não irei ater-me até onde se pode realmente defender uma defesa tão restrita da técnica - algo que me parece já um tanto problemático, pois fica a questão de como se pode separar com tanta segurança tais diferenças. Minha questão é outra. Pergunto: onde se encontra a razão de progenitores inférteis ou homossexuais, por exemplo, quanto à utilização da clonagem? A resposta dos defensores da clonagem é a de que os pais têm o direito a filhos que lhes sejam relacionados geneticamente.

Ora, é em resposta a esse segundo ponto que o princípio ético do cuidado criativo se mostra como possuindo um elemento mais positivo, isto é, como oferecendo um critério positivo do que deve ser feito pelos pais especialmente quanto à utilização de biotecnologias - em particular, a clonagem. Ora, tudo o que se afirma possui uma contrapartida, e a partir da contrapartida pode-se entender também o elemento positivo. É o que farei: partirei daquilo a que se opõe ao princípio do cuidado para entender o que ele ordena positivamente. Aqui, o que ele nos convida a pensar se desentende com um paradoxo flagrante da resposta dos defensores da clonagem, a saber: ao passo que se sugere ser "ingênuo pensar que o clone será como seu doador", defende-se, por outro lado, que não é ingênuo achar que a paternidade está relacionada ao sangue ou a uma herança genética unilateral (como é o caso do DNA mitocondrial, cuja única função, inclusive, é produzir energia). Mas está bem claro que na vontade de ter "filhos relacionados geneticamente" não se encontra implícito nada mais senão a verdadeira "falácia do determinismo genético", ou para expor de outra forma, a clonagem se quer contraditoriamente uma "solução à esterilidade severa [que] se inscreve assim na perspectiva de uma filiação sob condição genética, quer dizer, extremamente redutora sobre o plano simbólico" (FROGNEUX, 2001, p. 108). O paradoxo se torna ainda mais flagrante quando se percebe que dentre as possibilidades de solução para o problema da infertilidade, apenas duas parecem ter um resultado mais satisfatório do ponto de vista dos progenitores: o caso de progenitores homossexuais do sexo feminino e de progenitores heterossexuais em que a mulher é fértil e o homem é infértil. Nesses casos, em que o recurso a um doador de esperma foi recusado, o resultado é simplesmente idêntico: um dos progenitores não é, em termos de herança genética, propriamente 
pai biológico, mas apenas irmão de seu clone. Mesmo em relação à progenitora do óvulo é difícil saber até que ponto se pode chamá-la de mãe biológica. Para que fique claro: em ambos os casos - e note-se que estamos falando das duas melhores possibilidades - a clonagem implica necessariamente aquilo que chamarei, aqui, de o paradigma da adoção, isto é, a inserção da paternidade numa perspectiva não "redutora sobre o plano simbólico", ou se se preferir ainda, numa perspectiva onde ela não se aplica ao caso de reproduções "simbolicamente deficitárias" (cf. AUGÉ, 1999, p. 152).

É no sentido de superar tal déficit simbólico que o cuidado criativo tem antes como paradigma a adoção, e o que se afirma aí é o simples fato de que todo filho é adotado. Ao recusar toda orientação que se baseia numa lógica do mesmo, numa lógica refratária à alteridade, ou se se quiser ainda, numa crença pangenética ou mesmo na contemplação do umbigo genético, o cuidado criativo, ao privilegiar a adoção como paradigma, ensina que não é o sangue que conta, nem muito menos - descendo-se o labirinto biológico em escalas sempre menores - os genes, mas a philia. É ela que resguarda toda afiliação e paternidade. Há "filhos" que não são filhos, e aos quais os "pais (biológicos)" simplesmente deixam para traz: "filhos" não assumidos, deserdados.

Em especial, para se entender tudo o que está em jogo aqui, é preciso indicar o que o termo "criativo" significa em "cuidado criativo". Ele se opõe inicialmente a "procriativo" (por isso era necessário afastar qualquer tipo de parentesco com princípios como o de "autonomia procriativa" e "beneficência procriativa") - simplesmente não se trata de um princípio concernente à procriação, um fato puramente biológico. Nesse sentido, o termo "criativo" indica antes de tudo que, não o ato procriativo como tal em seus resultados, mas o paradigma da adoção é a essência da paternidade - termo que adotamos em sua acepção ampla (no sentido do inglês “parenting" antes que "fatherhood") -, pois a paternidade, bem salienta Marcel (1944, p. 136), “não é um puro dado de fato, ou... uma relação objetivamente determinável... seria completamente absurdo conceber a paternidade como um modo de causalidade, ou mesmo como uma finalidade”. Do mesmo modo que não é um evento biológico objetivo, a paternidade também não é um fato sociológico ou jurídico: não basta dar o nome a um filho e registrá-lo. Criativo também não se refere a um simples criar. Pai não é o que simplesmente cria. Uma das maiores características da sociedade contemporânea é a falência da paternidade, ou melhor: sua alienação, e isto justamente pela degeneração da paternidade ao mero criar. Aí o dispêndio de energia, próprio do que é criativo no cuidado, é simplesmente transferido para a escola, para a televisão, para a internet - e comprado pelo dinheiro, esta outra razão contemporânea para o não-ser-pai-e-mãe. Degenerada enquanto alienação, a paternidade não vai além de uma 
subpaternidade - para utilizar um termo mais correto e menos ambíguo do que o termo "hiperpaternidade [hyperparenting]" de Sandel (2007, p. 52).

Dessas últimas observações, gostaria de destacar, por fim, os dois elementos que caracterizam o que há de propriamente criativo no cuidar. Ele envolve, portanto, dispêndio de energia, engajamento e participação ativa - uma responsabilidade assumida e mantida. Mas só pode ser isto exatamente na medida em que abre espaço para a emergência de algo único e original - o filho que se realiza diante de nós, à medida que se cuida dele deixando-o ser o que ele autenticamente pode ser. Só aí, vemos por fim o que o cuidado criativo tem a ver com o princípio responsabilidade: a responsabilidade que exige a paternidade é uma responsabilidade não meramente biológica ou jurídica, mas é sobretudo a resposta a um apelo - na verdade, a um grito - de alteridade que não se realiza senão tendo a adoção como paradigma.

\section{REFERÊNCIAS BIBLIOGRÁFICAS}

ALLHOFF, F. 2004. Telomeres and the Ethics of Human Cloning. The American Journal of Bioethics $4(2)$ :

p. 29-31.

AUGÉ, Marc. 1999. Des individus sans filiation. In: ATLAN, Henry; AUGÉ, Marc; DELMASMARTY, M.; DROIT, R.-P.; FRESCO, N. (Eds.). Le Clonage Humain. Paris: Seuil.

BROCK, Dan W. 1998. Cloning Human Beings: An Assessment of the Ethical Issues Pro and Con. In: NUSSBAUM, Martha C. and SUNSTEIN, Cass R. (eds.). Clones and Clones: Facts and Fantasies about Human Cloning. New York: W. W. Norton, p. 141-67.

BUCHANAN, Allen et al. 2000. From Chance to Choice: genetics \& justice. New York: Cambridge University Press.

FROGNEUX, Nathalie. 2000. L'homme comme bouture de l'homme: quelques enjeux anthropologiques du clonage. Revue des Questions Scientifiques, 171, 1-2: p. 95-119.

GOFFI, Jean-Yves. 2007. The Harm of Being a Clone. In: FAGOT-LARGEAULT, Anne, RAHMAN, Shahid and TORRES, Juan Manuel (Eds.). The Influence of Genetics on Contemporary Thinking. Dordrecht, Springer, p. 151-163.

GRIFFIN, Harry. 2002. Cloning of Animals and Humans. In: BRYANT, John, LA VELLE, Linda Bargot and SEARLE, John (Eds.). Bioethics for Scientists. Chichester, UK: John Wiley \& Sons Ltd., p. 279-296.

HARRIS, John. 1997. "Goodbye Dolly?" The ethics of human cloning. Journal of Medical Ethics, 23, p. 353-360.

2004.

On Cloning. London:

Routledge.

2007. Enhancing Evolution: the ethical case for making

better people. Princeton, New Jersey: Princeton University Press. 
HOLM, Søren. 2001. A Life in the Shadow: One Reason Why We Should Not Clone Humans. In: KLOTZKO, Alerne Judith (Ed.). The Cloning Sourcebook. New York: Oxford New York, p. 203-207.

JONAS, Hans. 1966/2001. The Phenomenon of Life: Toward a Philosophical Biology. Evanston: Northwestern University Press.

. 1974/1980. Biological Engineering - A Preview. In: Philosophical Essays: From

Ancient Creed to Technological Man. Chicago: University of Chicago Press, 1980, p. 153-163. $569-582$. 1985/2004. Ethics and Biogenetic Art. Social Research, vol. 71, n 3, Fall 2004, p.

1985/1987. Technik, Medizin und Ethik: zur práxis des Prinzips Verantwortung. Frankfurt am Main: Suhrkamp.

1991. Erkenntnis und Verantwortung: Gespräch mit Ingo Hermann in der Reihe "Zeugen des Jahrhunderts“. Ingo Hermann (Hrsg.). Göttingen: Lamuv.

KAHN, Axel; PAPILLON, F. 1998. Copies conformes: le clonage en question. Paris: Nil Éditions.

KAHN, Axel. 2000. Clonage, filiation et alterité. In: Et l'Homme dans tout ça? Plaidoyer pour un humanisme moderne. Paris: Nil Éditions, p. 224-243.

KASS, Leon R. and WILSON, James Q. 1998. The Ethics of Human Cloning. Washington, DC: AEI Press.

KLOTZKO, Alerne Judith. 2007. Um Clone de si mesmo? A ciência e a ética da clonagem. Trad. Luciana Pudenzi. São Paulo: Loyola.

MARCEL, Gabriel. 1944. Homo Viator: Prolégomènes a une Métaphysique de L'Espérance. Paris: Aubier.

PENNISI, L. \& VOGEL, G. 2000. Clones: a hard act to follow. Science, 288, p. 1722-1727.

PRUSAK, Bernard G. 2008. Cloning and Corporeality. In: TIROSH-SAMUELSON, Hava \& WIESE, Christian (Ed.). The Legacy of Hans Jonas: Judaism and the Phenomenon of Life. Leiden - Boston: Brill, p. 315-344.

RENARD, J.-P. et al. 1999. Lymphoid Hypoplasia and Somatic Cloning. Lancet, 353, p. 14891491.

SANDEL, Michael. 2007. The Case against Perfection: Ethics in the Age of Genetic Engineering. Cambridge, MA: The Belknap Press of Harvard University Press.

SAVULESCU, Julian. 2001. Procreative Beneficence: Why We Should Select the Best Children. Bioethics, v. 15, issue 5-6, 2001, p. 413-426.

SINGER Peter. 2001. Cloning Humans and Cloning Animals. In: KLOTZKO, Alerne Judith (Ed.). The Cloning Sourcebook. New York: Oxford New York, p. 160-168.

SLOTERDIJK, Peter. 2000. La Domestication de L'Être: Pour un éclaircissement de la clairière. Traduction de l'allemand par Olivier Mannoni. Paris: Mille et une nuits. 
STEINBERG, Jesse R. 2005. Response to Fritz Allhoff, "Telomeres and the Ethics of Human Cloning" (AJOB 4:2). The American Journal of Bioethics 5(1): p. 27-28.

STEINBOCK, Bonnie. 2000. Cloning Human Beings: Sorting through the Ethical Issues. In: MACKINNON, Barbara (ed.) Human Cloning: Science, Ethics, and Public Policy. Urbana: University of Illinois Press, p. 68-84.

VALK, A. van der. 1997. Cloning as a Test Case of Autonomous Technology. Philosophy \& Technology 3: 1, p. 83-92. 